\title{
Nanopatterned acellular valve conduits drive the commitment of blood-derived multipotent cells
}

\author{
This article was published in the following Dove Press journal: \\ International Journal of Nanomedicine \\ 12 October 2016 \\ Number of times this article has been viewed
}

\author{
Rosa Di Liddo',2 \\ Paola Aguiari ${ }^{3}$ \\ Silvia Barbon ${ }^{1,2}$ \\ Thomas Bertalot' \\ Amit Mandoli' \\ Alessia Tasso' \\ Sandra Schrenk' \\ Laura lop ${ }^{3}$ \\ Alessandro Gandaglia ${ }^{3}$ \\ Pier Paolo Parnigotto ${ }^{2}$ \\ Maria Teresa Conconi ${ }^{1,2}$ \\ Gino Gerosa ${ }^{3}$ \\ 'Department of Pharmaceutical and \\ Pharmacological Sciences, University \\ of Padova, ${ }^{2}$ Foundation for Biology \\ and Regenerative Medicine, Tissue \\ Engineering and Signaling ONLUS, \\ ${ }^{3}$ Department of Cardiac, Thoracic \\ and Vascular Sciences, University \\ of Padova, Padova, Italy
}

\begin{abstract}
Considerable progress has been made in recent years toward elucidating the correlation among nanoscale topography, mechanical properties, and biological behavior of cardiac valve substitutes. Porcine TriCol scaffolds are promising valve tissue engineering matrices with demonstrated self-repopulation potentiality. In order to define an in vitro model for investigating the influence of extracellular matrix signaling on the growth pattern of colonizing blood-derived cells, we cultured circulating multipotent cells (CMC) on acellular aortic (AVL) and pulmonary (PVL) valve conduits prepared with TriCol method and under no-flow condition. Isolated by our group from Vietnamese pigs before heart valve prosthetic implantation, porcine $\mathrm{CMC}$ revealed high proliferative abilities, three-lineage differentiative potential, and distinct hematopoietic/endothelial and mesenchymal properties. Their interaction with valve extracellular matrix nanostructures boosted differential messenger RNA expression pattern and morphologic features on AVL compared to PVL, while promoting on both matrices the commitment to valvular and endothelial cell-like phenotypes. Based on their origin from peripheral blood, porcine CMC are hypothesized in vivo to exert a pivotal role to homeostatically replenish valve cells and contribute to hetero- or allograft colonization. Furthermore, due to their high responsivity to extracellular matrix nanostructure signaling, porcine CMC could be useful for a preliminary evaluation of heart valve prosthetic functionality.
\end{abstract}

Keywords: blood-derived multipotent cells, self-repopulation potential, guided tissue engineering, TriCol decellularization procedure, ECM nanostructure signaling

\section{Introduction}

Scaffolds for valve tissue engineering ${ }^{1}$ are required to express structural properties enabling cell ingrowth upon implantation in vivo. In particular, the surface morphology or nanotopography has been demonstrated to control cell behavior on biomaterials and thus tissue formation and function. ${ }^{2,3}$

Despite still showing clinical disadvantages, ${ }^{4-8}$ that is, calcification and structural degeneration, 9,10 biological prostheses are commonly used for the replacement of diseased heart valves. In the last decade, several approaches based on decellularized xeno- or homografts have been developed to obtain optimal valve substitutes. In this scenario, tissue-engineered heart valve represents a promising therapeutic strategy to guarantee in vivo tissue remodeling and repair during lifetime. ${ }^{11,12}$

As demonstrated by several studies, the success of valve substitutes is strictly dependent on the ability of scaffold to provide the correct biophysical cues for cell adhesion, migration, proliferation, and differentiation. The heart valves are characterized by a highly compartmentalized structure enforcing mechanical adaptation to environmental changes. ${ }^{13}$ The architectural pattern is complex and comprises 1) valvular endothelial cells (VECs) at the blood-contacting surfaces and valvular interstitial cells (VICs) in
Correspondence: Rosa Di Liddo Pharmacological Sciences, University of Padova, Via Marzolo 5, I-35। 3 I

Padova, Italy

Tel +390498275636

Fax +390498275366

Email rosa.diliddo@unipd.it 
the inner layers and 2) extracellular matrix (ECM), organized into a tri-layered structure ensuring high tensile strength and low flexural stiffness. ${ }^{13,14}$

The maintenance of structural and functional ECM integrity is highly relevant to preserve the mechanical behavior of decellularized valve matrices and avoid in vivo graft deterioration. ${ }^{6}$ Elastin defragmentation and extraction of glycosaminoglycans and water have been described following several decellularization procedure-based trypsin/ Triton X-100 treatment or sodium dodecyl sulfate. ${ }^{4,15}$ In contrast, sodium cholate- and deoxycholate-based methods are useful to achieve fully nude matrices, with high in vitro and/or in vivo repopulation potentialities. ${ }^{16-19}$

Recently, the development of decellularized xenografts or homografts with self-regeneration potential is considered as an attractive option to obtain novel viable replacements granting longer durability and avoiding the extensive in vitro cell conditioning. Various studies have already reported in situ recellularization of decellularized xenografts and homografts in animal models highlighting variable success rate in dependence on the adopted decellularization method or used graft typology (xenograft or homograft). ${ }^{20-23}$

Spina et $\mathrm{al}^{24}$ set up a technique for decellularization of heart valve leaflets minimally affecting collagenous elastic network. Combining Triton X-100 and cholate, the so-called TriCol procedure, has been reported to guarantee 1) the complete tissue decellularization, that is functional to control the development of calcification process; ${ }^{24} 2$ ) the removal of alpha-gal xenoantigens for avoiding the rejection of xenogenic grafts, ${ }^{25} 3$ ) the preservation of valve hemodynamic profile and performance; and 4) in vitro full biocompatibility with valve interstitial cells ${ }^{26}$ and bone marrow mesenchymal stem cells (BM-MSCs). ${ }^{16}$ Largely characterized by their composition of glycosaminoglycans, proteoglycans, ECM filaments, ${ }^{24,27}$ and nonpreconditioned TriCol heart valves showed a good hemodynamic profile and stable structural integrity in a long-term follow-up performed in allogeneic animal model. ${ }^{18}$

There is a general agreement that bone marrow stromal cells are recruited into circulation upon tissue damage or graft implantation and are involved in tissue repair and regeneration. ${ }^{28-30}$ Moreover, many authors suggest that stem cells could be mobilized by pharmacological treatment (ie, anesthesia) from their specific niche and circulate in the bloodstream, thereby participating in the regeneration processes of peripheral tissues. ${ }^{31}$ Recently, great interest has been focused on blood-derived stem cells in heart valve surgery as potential physiological and autologous mediators of the so-called guided valve tissue engineering.
To date, fibroblast-like multipotent cells with proliferative and multidifferentiative properties but distinct immunophenotypic features have already been identified in peripheral blood of different species of adult animals, such as guinea pig, ${ }^{32}$ rabbit, ${ }^{33}$ dog, ${ }^{34}$ mouse, ${ }^{35}$ rat,,${ }^{36}$ and humans. ${ }^{37,38}$

While processing the peripheral blood of Vietnamese pigs (VPs) sedated before heart valve surgery, we recently isolated a population of multipotent adherent cells that fulfill some MSC criteria, as defined by the International Society for Cellular Therapy. ${ }^{29}$ Due to similarities with human circulating cells previously described, ${ }^{38}$ we have named these cells "porcine circulating multipotent cells" (pCMC) and experimentally used to explore the repopulation potential of porcine heart valves decellularized with TriCol procedure (Figure 1). Under no-flow culture condition, pCMC have been showed to be differentially stimulated by AVL and PVL and expressed gene markers correlatable to VIC- and VEC-like phenotypes.

\section{Materials and methods Scaffold preparation}

Aortic valve (AV) and pulmonary valve (PV) were isolated from common breeding piglets ( 3 to 4 months old) and used for preparing acellular aortic valve leaflets (AVL) and acellular pulmonary valve leaflets (PVL). Hearts were washed in sterile phosphate-buffered saline (PBS) supplemented with penicillin $100 \mathrm{U} / \mathrm{mL}$, streptomycin $100 \mathrm{mg} / \mathrm{mL}$, and amphotericin B $250 \mathrm{mg} / \mathrm{mL}$ (all from Sigma-Aldrich Co., St Louis, MO, USA). Decellularization was performed by TriCol treatment as previously described by Bertipaglia et al. ${ }^{26}$ Nucleic acids (DNA/RNA) were removed using two successive 24 -hour periods at $37^{\circ} \mathrm{C}$ under constant stirring according to endonuclease Benzonase protocol (Merck Chemicals Ltd, Nottingham, UK). ${ }^{24}$ The effective DNA removal in TriCOL-treated valves was verified by 4,6diamidino-2-phenylindole (DAPI) staining of histological sections ( $5 \mu \mathrm{m}$ thick) of AVL and PVL. Before cell seeding, AVL and PVL were preconditioned with bovine fibronectin $\left(10 \mu \mathrm{g} / \mathrm{cm}^{2}, 24\right.$ hours at $37^{\circ} \mathrm{C}$; Calbiochem, Billerica, MA, USA) to enhance the adhesion of pCMC.

\section{Blood cells}

Samples $(10 \mathrm{~mL})$ were collected from 9 months to 12 months old healthy VPs that were sedated according to the procedure previously reported. ${ }^{19} \mathrm{VPs}$ were provided by CISRA Institute (120TO025 - ASL 3 Collegno, Torino, Italy). All experiments were performed under authorization of the Italian Ministry of Health (project registration number 27/08 C16), according to the principles given by ISO 10993-2 (ISO 10993-2 


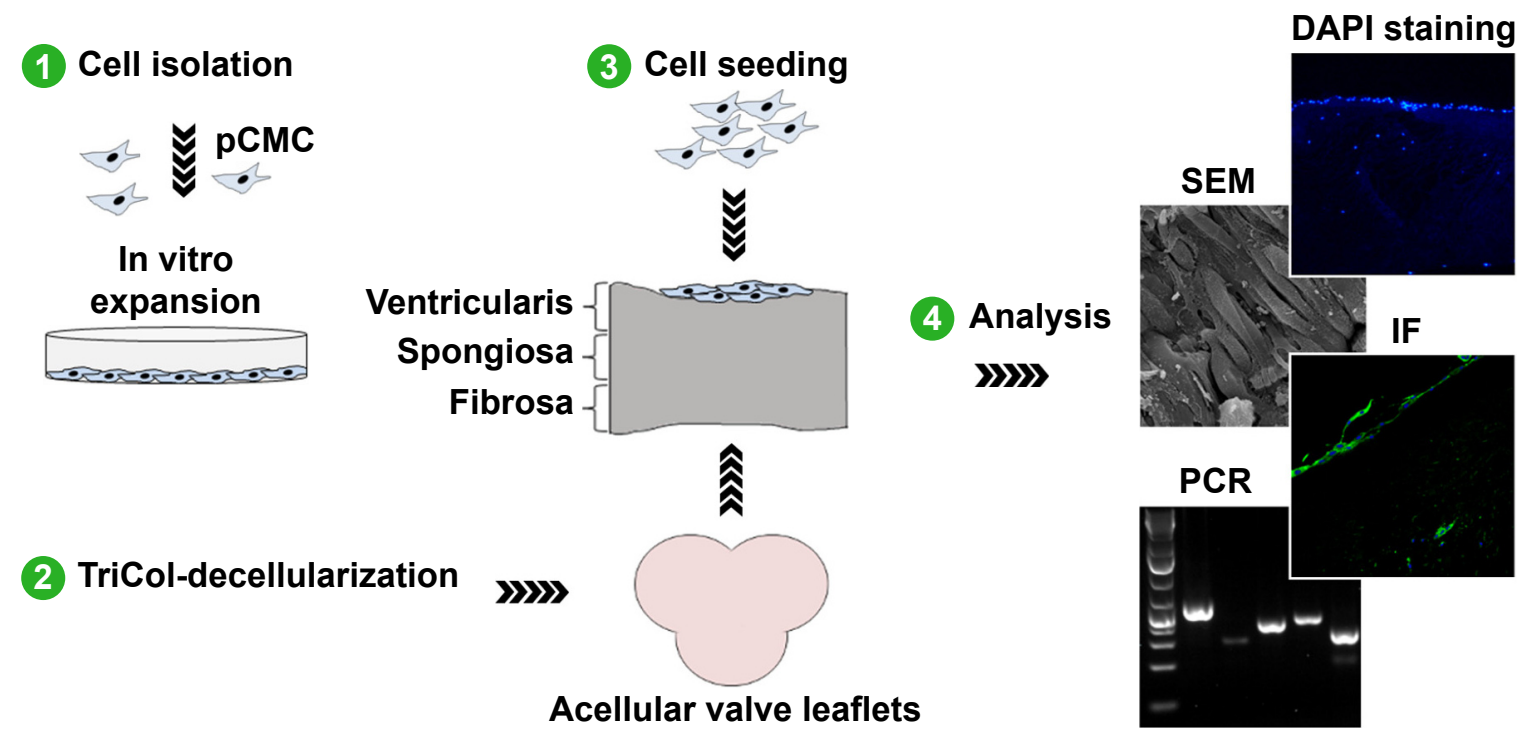

Figure I Experimental design for in vitro study of $\mathrm{PCMC}$-seeded matrices.

Abbreviations: PCMC, porcine circulating multipotent cells; DAPI, 4,6-diamidino-2-phenylindole; SEM, scanning electron microscopy; PCR, polymerase chain reaction; IF, immunofluorescence.

Biological Evaluation of Medical Devices part 2: Animal Welfare Requirements: EN ISO 10993, 2003).

Cell isolation was performed using density gradient separation technique and Histopaque-1077 (Sigma-Aldrich Co.). Blood samples were diluted 1:1 with PBS and carefully layered on Histopaque-1077 solution. Following centrifugation at $400 \times g, 4^{\circ} \mathrm{C}$, mononuclear cells were collected, washed in PBS solution, and then seeded $\left(1 \times 10^{6}\right.$ cells $\left./ \mathrm{cm}^{2}\right)$ in polystyrene culture dishes (BD, Franklin Lakes, NJ, USA). Cultures were cultivated at $37^{\circ} \mathrm{C}, 95 \%$ humidity, and $5 \% \mathrm{CO}_{2}$, in proliferation culture medium prepared with alpha-modified eagle medium without nucleosides, $16.5 \%$ fetal bovine serum (FBS), $1 \%$ antibiotic solution, and $1 \%$ glutamax (all from Thermo Fisher Scientific, Waltham, MA, USA). When fibroblast colonies (fibroblast colony-forming units) were detected, culture medium was changed and cell expansion was performed. At $80 \%$ confluence, cells were detached using $0.02 \%$ ethylenediaminetetraacetic acid $/ 0.25 \%$ trypsin solution (Sigma-Aldrich Co.), and subcultures were prepared with a seeding density of $5 \times 10^{3}$ cells $/ \mathrm{cm}^{2}$. All cultures were observed daily by optical microscope DM/IL (Leica Microsystems, Wetzlar, Germany), and pictures were taken with Nikon Digital Sight Ds-SMCc camera (Nikon Corporation, Tokyo, Japan).

\section{Scanning electron microscopy}

The samples were fixed with $3 \%$ glutaraldehyde prepared in $0.1 \mathrm{M}$ sodium cacodylate buffer ( $\mathrm{pH}$ 7.4) (Sigma-Aldrich Co.), for 24 hours, at $4^{\circ} \mathrm{C}$. After washing in sodium cacodylate buffer, the dehydration of cells was carried out through a graded series of ethanol and submitted to critical point drying.
Finally, the samples were coated with gold and observed by microscope JSM Jeol 6490 (JEOL, Tokyo, Japan).

\section{Immunophenotyping}

Short- (eighth generation) and long- (36th generation) term cultures were analyzed by flow cytometry for the expression of hematopoietic, endothelial, and MSC markers using anti-pig antibodies raised against target proteins reported in Table 1 and 2. The expression of alpha-smooth muscle

Table I Antibodies used for FCM and immunofluorescence analysis

\begin{tabular}{ll}
\hline & Manufacturing company \\
\hline Primary antibodies & \\
PE-Cy7 mouse anti-pig CD34 & BD Biosciences \\
Mouse anti-pig CD44 & AbD Serotec \\
PE mouse anti-pig CD45 & Santa Cruz Biotecnology, Inc. \\
PE mouse anti-pig CD90 & Santa Cruz Biotecnology, Inc. \\
PE mouse anti-pig CDI05 & Santa Cruz Biotecnology, Inc. \\
Mouse anti-pig CDI06 & AbD Serotec \\
Mouse anti-pig CDI33 & Miltenyi Biotec \\
Mouse anti-pig CXCR4 & Santa Cruz Biotecnology, Inc. \\
Mouse anti-pig SLA-DR & AbD Serotec \\
FITC rabbit anti-pig $\alpha-S M A$ & Abcam \\
Rabbit anti-pig vWF & Abcam \\
Secondary antibodies & \\
PE goat anti-mouse & Santa Cruz Biotecnology, Inc. \\
FITC goat anti-mouse & AbD Serotec \\
AlexaFluor ${ }^{\circledR 88}$ goat anti-rabbit & Thermo Fisher Scientific \\
Isotype controls & \\
PE isotype control & Santa Cruz Biotecnology, Inc. \\
PE-Cy7 isotype control & BD Biosciences \\
\hline
\end{tabular}

Abbreviations: FCM, flow cytometry; PE, phycoerythrin; PE-Cy7, phycoerythrincyanine7; CXCR4, C-X-C chemokine receptor type 4; SLA-DR, swine leukocyte antigen DR; FITC, fluorescein isothiocyanate; $\alpha$-SMA, alpha-smooth muscle actin; vWF, von Willebrand factor. 
actin ( $\alpha$-SMA) was evaluated by immunofluorescence (IF) using a fluorescein isothiocyanate-conjugated rabbit anti-pig $\alpha$-SMA antibody (Abcam, Cambridge, UK). After mounting with Fluoro-Gel II solution containing DAPI (Electron Microscopy Sciences, Hatfield, PA, USA), the samples were analyzed using a Leica TCS SP5 confocal microscope (Leica Microsystems). As negative controls, isotype or secondary antibodies-matched samples were used (Table 1). Flow cytometry analysis was performed using MOFLO HighSpeed Cell Sorter (DAKO-Beckman Coulter Inc, Brea, CA, USA) and Summit 4.3 software (DAKO-Beckman Coulter Inc.). Data were reported as mean percentage of positive cells $\pm \mathrm{SD}$ of three independent experiments performed in triplicate.

\section{Proliferation capacity}

The proliferation and senescence rate of pCMC was evaluated culturing for 36 consecutive passages by seeding in triplicate each generation at a density of $5 \times 10^{3}$ cells $/ \mathrm{cm}^{2}$. At an interval of 24 hours, the cells were detached using ethylenediaminetetraacetic acid/trypsin solution and counted. The average number of cells \pm SD for each passage was used to calculate the doubling population time.

\section{Differentiative plasticity}

The cells were seeded at a density of $3 \times 10^{3}$ cells $/ \mathrm{cm}^{2}$ and induced to differentiate under the conditions described later. In parallel, cells cultured in proliferation medium were used as control. After 7 days and 14 days, cytochemical, colorimetric, and IF analyses were performed to confirm the lineage-specific differentiation.

\section{Adipogenic induction}

The samples were cultured in Dulbecco's Modified Eagle's Medium high-glucose medium (Sigma-Aldrich Co.) supplemented with 10\% FBS (Thermo Fisher Scientific), 1\% antibiotic solution (Sigma-Aldrich Co.), and adipogenic supplements (1 mM dexamethasone, $0.5 \mathrm{mM}$ 3-isobutyl-1-methylxanthine, $10 \mathrm{mg} / \mathrm{mL}$ insulin, $60 \mathrm{mM}$ indomethacin) (all from SigmaAldrich Co.). To detect intracellular lipid droplets, the cells were fixed with $10 \%$ formalin solution (Sigma-Aldrich Co.) and stained with Oil Red O solution ( $5 \mathrm{mg} / \mathrm{mL}$ in isopropanol) (Sigma-Aldrich Co.). Nuclei were counterstained with hematoxylin (Sigma-Aldrich Co.) according to standard procedure.

\section{Osteogenic induction}

For the analysis of osteogenic potentiality, we cultured pCMC using collagen I-coated plates (Sigma-Aldrich Co.) and alpha-modified eagle medium supplemented with 10\% FBS, $1 \%$ antibiotic solution, and osteogenic supplements (100 nM dexamethasone, $10 \mathrm{mM} \beta$-glycerophosphate, $0.05 \mathrm{mM}$ ascorbic acid-2-phosphate) (all from Sigma-Aldrich Co.). To verify the formation of calcium deposits in stimulated cultures, an osteogenesis assay kit (EMD Millipore, Billerica, MA, USA) was used. After fixation with $10 \%$ formalin solution for 15 minutes, the samples were washed twice with distilled water and then incubated with Alizarin Red S according to manufacturer's instructions. After the addition of ammonium hydroxide, the amount of the extracted Alizarin Red dye was measured at $562 \mathrm{~nm}$ and quantified using an Alizarin Red S standard curve. Data were expressed as the mean concentration $(\mu \mathrm{M}) \pm \mathrm{SD}$ of three separate experiments performed in triplicate. Unstimulated samples were used as control. Statistical significance was calculated using Student's $t$-test comparing to controls.

\section{Cardiomyogenic induction}

Cells were treated with Dulbecco's Modified Eagle's Medium low glucose (Thermo Fisher Scientific), 20\% FBS (SigmaAldrich Co.), 1\% antibiotic solution (Sigma-Aldrich Co.), 1\% glutamax (Thermo Fisher Scientific), and 6 mM 5-azacytidine (Sigma-Aldrich Co.). To assess the specific lineage induction, we performed an indirect IF assay using Vectastain ABC system (Vector Laboratories, Inc., Burlingame, CA, USA) and mouse anti-pig $\alpha$-cardiac actin (actin alpha cardiac muscle 1), mouse anti-pig cardiac troponin $\mathrm{T}$, and mouse anti-pig phospholamban primary antibodies (all from Acris, San Diego, CA, USA). The analysis of samples was executed with Leica TCS-SP5 confocal microscope and LAS AF software (Leica Microsystems).

\section{Cell seeding on acellular valve matrices}

After several washings in PBS solution, the valve matrices were maintained in $50 \%$ FBS solution for 12 hours at $37^{\circ} \mathrm{C}$ before cell seeding. The cells were seeded in proliferation medium at a density of $6.5 \times 10^{5}$ cells on the ventricularis side of leaflets $\left(0.5 \mathrm{~cm}^{2}\right)$. Using no-flow condition, the samples were cultured in vitro up to 35 days performing the change of medium every 2 days. At different time points ( 7 days, 14 days, 28 days, and 35 days), the constructs were fixed and analyzed by reverse transcription-polymerase chain reaction (RT-PCR), scanning electron microscopy (SEM), and IF staining. Native AV and PV were used as reference.

\section{One-step RT-PCR}

Total cellular RNA was extracted using TRIzol ${ }^{\circledR}$ (Thermo Fisher Scientific). After treatment with RNase-Free DNase 
Set (Qiagen NV, Venlo, the Netherlands), the samples were quantified by measuring the absorbance at $260 \mathrm{~nm}$. Fifty nanograms of RNA were reverse transcribed and amplified using One Step RT-PCR Kit (Qiagen) according to the manufacturer's instructions. Transcripts encoding endothelial, VIC, VEC, and ECM proteins were investigated using oligonucleotides listed in Table 3. PCR products were electrophoresed on 2\% agarose gel (Sigma-Aldrich Co.), prestained with GelRedTM and then visualized by UV transilluminator Gel Doc 2000 (Bio-Rad Laboratories Inc., Hercules, CA, USA). The quantification of amplicon density band was calculated for each target gene using ImageLab software (Bio-Rad Laboratories Inc.) considering three independent experiments performed in triplicate. Data were reported as ratio within target and housekeeping (glyceraldehyde 3-phosphate dehydrogenase) gene expression level. Statistical significance was calculated by the Wilcoxon test comparing the expression profile of 1) pCMC grown on polystyrene dishes and control native valves ( $\mathrm{AV}$ and $\mathrm{PV}$ ) or 2) pCMC cultured on valve leaflets against samples cultured for 7 days (D7).

\section{IF staining}

To evaluate the growth of $\mathrm{pCMC}$ on AVL and PVL surface matrices, histological sections of constructs and native AV and PV were prepared, fixed in $10 \%$ formalin solution at different time points of culture (D7, D14, D28, and D35), and thus stained with Fluoro-Gel II solution containing DAPI. In parallel, the expression of CD44, CD106, and von Willebrand factor was evaluated by indirect IF and using the antibodies listed in Table 1. In parallel, secondary antibody-matched samples were used as negative controls. The acquisition of images was performed using a Leica TCS SP5 confocal microscope.

\section{Results}

\section{Cell isolation and morphological study}

After 15-20 days from seeding, typical fibroblast colonyforming units were detected with a frequency of $0.7 \pm 0.02 / 10^{6}$ nucleated cells. The cells gave rise in short-term cultures (from 0 to 10th passage) to heterogeneous populations with spindle-shaped morphology (Figure 2A) and pseudopodialike membrane projections (Figure 2B). After prolonged in vitro expansion (from 11th to 36th passages), the morphological features were retained (Figure 2C).

\section{Growth kinetics}

Our data evidenced a linear relationship between population doublings and generation number with a doubling time of $\sim 16$ hours (Figure 2D).

\section{$\mathbf{E}$}

C

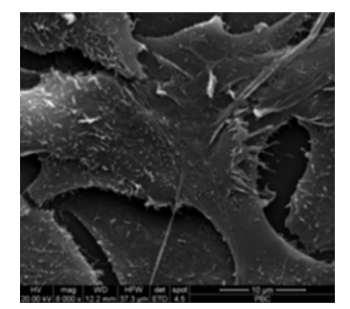

D

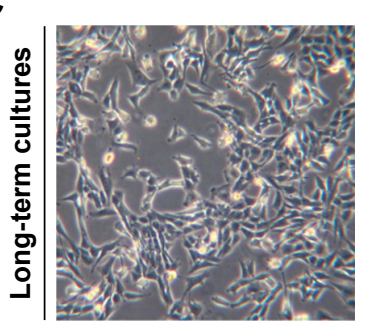

B
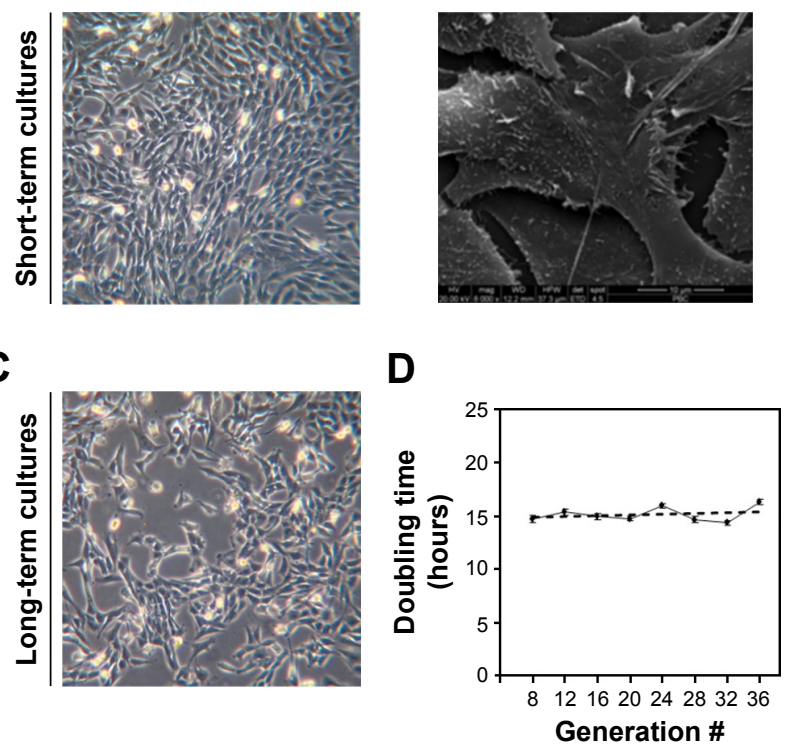

\begin{tabular}{ll}
\hline Antigen & \% positive cells \pm SD \\
\hline CD34 & $24.1 \pm 1.5$ \\
CD44 & $97.6 \pm 2.6$ \\
CD45 & ND \\
CD90 & $8.9 \pm 1.2$ \\
CD105 & ND \\
CD106 & $21.5 \pm 2.9$ \\
CD133 & $1.6 \pm 0.3$ \\
CXCR4 & ND \\
SLA-DR & $13.1 \pm 1.2$ \\
\hline
\end{tabular}

$\mathbf{F}$

Antigen $\%$ positive cells \pm SD

CD34 9.8 \pm 1.3

CD44 $95.3 \pm 1.5$

CD45 ND

$\mathrm{CD} 90 \quad 4.1 \pm 0.8$

CD105 ND

CD106 23.4 \pm 1.7

CD133 $1.0 \pm 0.2$

CXCR4 ND

SLA-DR $\quad 9.8 \pm 1.4$

Figure 2 Phenotypic characterization of PCMC cells.

Notes: Analysis of morphological, proliferative, and immunophenotypic features of short-term (0-10th passages) (A, B, E, G) and long-term (I I th-36th passages) (C, F, G) pCMC cultures. (A, C) Phase-contrast microscopy. (B) SEM analysis. (D) Growth kinetics and calculation of doubling population time over a total of 36 divisions. (E, F) Flow cytometric analysis. Data are reported as mean percentage of positive cells \pm SD of three independent experiments performed in triplicate. (G) IF detection of $\alpha$-SMA. Bar: $25 \mu \mathrm{m}$.

Abbreviations: PCMC, porcine circulating multipotent cells; IF, immunofluorescence; ND, not detected; CXCR4, C-X-C chemokine receptor type 4; SLA-DR, swine leukocyte antigen DR; $\alpha$-SMA, alpha-smooth muscle actin; DAPI, 4,6-diamidino-2-phenylindole. 


\section{Immunophenotype}

The immunophenotype of pCMC was determined by flow cytometry (Figure 2E and F) and IF (Figure 2G) using the antibodies listed in Table 1. The short-term cultures were shown to express hematopoietic (CD34), endothelial (CD133), and typical MSC markers (CD44, CD106, CD90, $\alpha$-SMA) (Figure 2E and $\mathrm{G})$. CD45, a hematopoietic lineage-restricted antigen, CD105, a receptor for TGF- $\beta 1$ and $-\beta 3$, and C-X-C chemokine receptor type 4, a stromal-derived-factor-1 receptor, were not detected (Figure 2F and G). Swine leukocyte antigen DR was present on a small subpopulation and showed to be modulated during in vitro culture (Figure 2E and F). Upon long-term expansion, the expression level of CD44, CD106, CD133, and $\alpha$-SMA unchanged, while a decreased positivity for $\mathrm{CD} 34$ and CD90 was observed (Figure 2F and G). As shown in Table 2, the comparison with other blood-derived stem cells confirmed for $\mathrm{pCMC}$ a distinctive immunophenotype.

\section{Differentiative potential}

After specific differentiation induction, the plasticity of pCMC toward adipogenic, osteogenic, and cardiomyogenic lineage was demonstrated evaluating the accumulation of lipid droplets (Figure 3A), the synthesis of mineralized ECM (Figure 3B), and the expression of specific cardiomyogenic markers such as phospholamban (Figure 3C), actin alpha cardiac muscle 1 (Figure 3D), and cardiac troponin T (Figure 3E). Upon prolonged in vitro expansion, the differentiative response of $\mathrm{pCMC}$ unchanged.

Table 2 Immunophenotypic profile of different classes of circulating stem cells

\begin{tabular}{lllllll}
\hline Marker & pCMC & BM-MSC & HSC & EP $_{\mathbf{c}}$ BD-MSC & MOMCs \\
\hline CDI4 & - & - & - & - & & + \\
CD34 & + & - & $+l-$ & + & - & + \\
CD44 & + & + & $+l-$ & - & + & - \\
CD45 & - & - & + & - & - & + \\
CD90 & + & + & + & + & + & - \\
CDI05 & - & + & + & + & + & + \\
CDI06 & + & + & + & + & + & - \\
CDI33 & + & - & + & + & & - \\
CXCR4 & - & + & + & + & & - \\
HLA-DR/SLA-DR & + & - & - & - & + \\
Collagen I & + & + & - & + & + \\
$\alpha-S M A$ & + & + & - & - & - \\
vWF & - & - & - & + & \\
\hline
\end{tabular}

Notes: +, expression; -, no expression. Data from studies. ${ }^{29,45-50}$

Abbreviations: PCMC, porcine circulating multipotent cells; BM-MSC, bone marrow mesenchymal stem cells; HSC, hematopoietic stem cells; EPc, endothelial progenitor cells; BD-MSC, blood-derived mesenchymal stem cells; MOMCs, monocyte-derived multipotential cells; CXCR4, C-X-C chemokine receptor type 4; HLA-DR, human leukocyte antigen; SLA-DR, swine leukocyte antigen DR; $\alpha-S M A$, alpha-smooth muscle actin; vWF, von Willebrand factor.

\section{Cellular response to valve matrix signaling \\ Gene expression study}

Using the oligonucleotides listed in Table 3, the gene expression pattern of native heart valves was defined exploring clusters of messenger RNAs (mRNAs) relevant to VICs and VECs functionality or valve regeneration process (Figures 4 and S1). Before seeding on valve matrices, pCMC showed an active gene transcription for ECM components (fibrillin [FBN1], emilin [EMILIN1], collagen I [COL1A1], collagen III [COL3A1], and tenascin C [TNC]), angiogenic/cytoskeleton reorganization markers (caldesmon 1 [CALD1]), and matrix degrading enzymes (metalloproteinase [MMP] 2). The growth on AVL and PVL affected the gene expression of pCMC reducing drastically mRNA synthesis at early and intermediate phases (from D7 to D28) while promoting a differential gene expression pattern at longer time point (D35) between engineered aortic and pulmonary conduits. In particular, pCMC cultured on AVL showed a significant mRNA expression of MMP2, MMP13, COL3A1, COL4A1, TNC, and vascular endothelial growth factor A (VEGFA). In contrast, the cell interactions with PVL were effective to boost the transcription of COL3A1, FBN1, EMILIN1, COL1A1, TNC, CALD1, and VEGFA. As shown by DAPI staining in Figures 5 and 6 , pCMC colonized the surface of both ventricularis and fibrosa layers, thus suggesting that the cellular response evaluated by gene expression study could be mediated by the interactions of pCMC with both inflow and outflow layers.

\section{Morphological analysis of pCMC-seeded matrices}

Using AV (Figure 5A) and PV (Figure 6A) as control, the morphological study of the inflow surface of acellular matrices was performed by SEM before (Figures $5 \mathrm{~A}[\mathrm{a}]$ and $6 \mathrm{~A}[\mathrm{a}]$ ) and after (Figures 5C, E, G, and I and 6C, E, G, and I) the seeding of pCMC. In parallel, DAPI staining was used to investigate the TriCol efficacy of cellular removal and to track the growth and distribution of pCMC on acellular matrices during 35 days of in vitro culture. As shown in Figures 5 and 6, the ventricularis surface of TriCol-treated valves was demonstrated to be completely decellularized and formed of ECM fibrillary network (Figures $5 \mathrm{~A}[\mathrm{a}]$ and $6 \mathrm{~A}[\mathrm{a}]$ ). The cells adhered to both valve conduits and spread, acquiring fibroblastic morphology from early-(D7) to intermediate-(D35) in vitro culture (Figures 5C-I and $6 \mathrm{C}-\mathrm{I})$. The adhesion to matrix was preserved for all the evaluation period of 35 days, and the growth was detected by DAPI staining at the ventricularis (early phase) and fibrosa layers (intermediate/late phase). As expected from engineered constructs cultured in vitro under no-flow condition, 

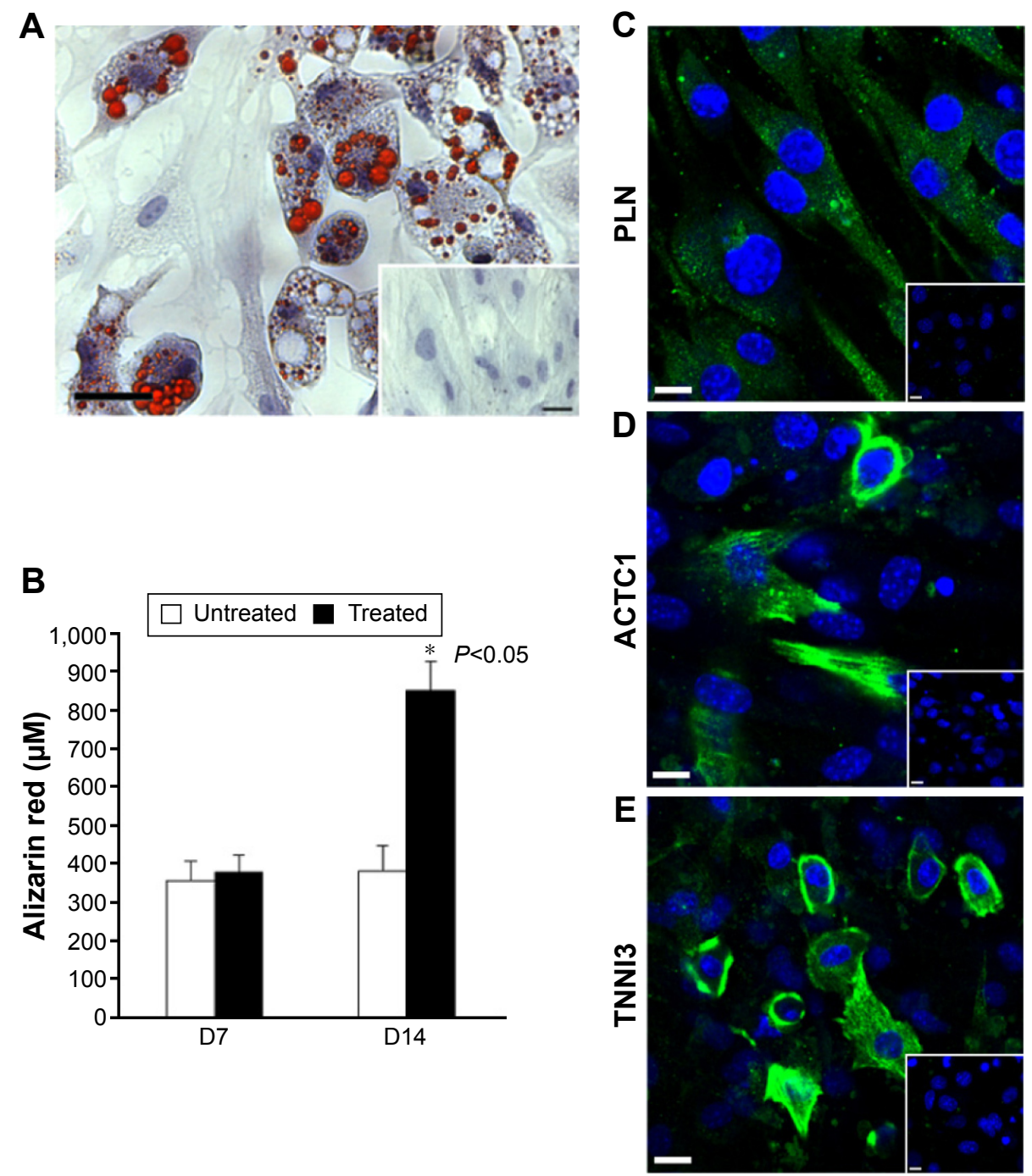

Figure 3 Study of differentiative potentialities of PCMC versus adipogenic (A), osteogenic (B), and cardiomyogenic (C-E) lineages.

Notes: (A) Detection of cytoplasmic lipid droplets by Oil red O staining after adipogenic stimulation for 14 days. Nuclei were counterstained with hematoxylin. Data from unstimulated samples were reported in the right down corner. Bar: $25 \mu \mathrm{m}$. (B) Alizarin red staining to evaluate calcium deposits in cultures grown in osteogenic (treated) and proliferative (untreated) medium for 7 days (D7) and I4 days (DI4). The amount of extracted Alizarin red dye was measured at $562 \mathrm{~nm}$ and quantified using an Alizarin red $\mathrm{S}$ standard curve. Data were expressed as the mean concentration $(\mu \mathrm{M}) \pm \mathrm{SD}$ from three separate experiments performed in triplicate. Statistical significance was calculated using Student's $t$-test comparing to untreated samples ( $* P \leq 0.05)$. IF analysis of (C) PLN, (D) ACTCI, and (E) TNNI3 in cells stimulated for I4 days with cardiomyogenic medium. Unstimulated cells (right down corner) were used as control. Nuclei were counterstained with DAPI. Scale bar: I0 $\mu \mathrm{m}$.

Abbreviations: pCMC, porcine circulating multipotent cells; IF, immunofluorescence; PLN, phospholamban; ACTCI, cardiac muscle alpha actin; TNNI3, cardiac troponin I type 3; DAPI, 4,6-diamidino-2-phenylindole.

no DAPI-stained cells were detectable in the inner parts of matrices (Figures $5 \mathrm{~B}[\mathrm{~b}]$ and $6 \mathrm{~B}[\mathrm{~b}]$ ) compared to native tissues (Figures 5A and $\mathrm{B}$ and $6 \mathrm{~A}$ and $\mathrm{B}$ ).

Interestingly, SEM analysis provided insights into the effects of ECM nanostructures and physical forces on cell changes in cytoskeletal actin filaments and spatial orientation. It is known that the ventricularis contains multidirectionally oriented collagen fibers and an extensive network of elastic fibers mostly oriented perpendicular to the free edge of the cusp. As predictable, a more tight distribution pattern of collagen and elastic fibers was observed in AVL ventricularis compared to PVL inflow layer (Figures 5 and 6). The
SEM of engineered conduits showed that $\mathrm{pCMC}$ retained elongated morphology during in vitro culture on AVL matrix and aligned parallel to the long axis. Conversely, the cells grown on PVL matrices switched from typical fibroblasticlike morphology to polygonal shape at D28, coinciding with the increased mRNA synthesis of ECM components. In both AVL and PVL, pCMC resembled morphologically the mature endothelial cells of the corresponding native valves.

\section{Immunofluorescence}

We demonstrated that TriCol matrices preserve long-term survival of $\mathrm{pCMC}$ by investigating the protein expression of 
Table 3 Oligonucleotides used for the qPCR analysis

\begin{tabular}{|c|c|c|c|c|}
\hline Gene & Abbreviation & Primer sequences & Accession & Amplicon length \\
\hline \multirow[t]{2}{*}{ Matrix metalloproteinase-2 } & MMP2 & F: CGGACAAGAGTTGGCTGTGCAAT & NM_214192.I & 506 bp \\
\hline & & R: AGCTGGGTGGAAGAGAACACAGTT & & \\
\hline \multirow[t]{2}{*}{ Matrix metalloproteinase- 13} & MMPI3 & F: TCTTCTTGAGCTGGACCCACTGTT & FJ263939.I & 288 bp \\
\hline & & R: ACCTCTAAGCCGAAGAAAGACTGC & & \\
\hline \multirow[t]{2}{*}{ Fibrilin } & FBNI & F: TGGGATTTACCGTGCTTTAGCGT & NM_00I00I77I.I & $381 \mathrm{bp}$ \\
\hline & & R: CTCTGGCACAGACAGTGGTCATCA & & \\
\hline \multirow[t]{2}{*}{ Emilin } & EMILINI & F: ACAAGACAGTGACGGAGATGGAGT & XM_003I25303.I & 399 bp \\
\hline & & R: TGCTGCTGCATCTCATTGAGGGTT & & \\
\hline \multirow[t]{2}{*}{ Alpha-I type I collagen } & COLIAI & F: GAACCAAAGGGCCCAAAGGTGAAA & NM_00I243655.I & $301 \mathrm{bp}$ \\
\hline & & R: AGAGGGACCTTTCTCACCAGCAAA & & \\
\hline \multirow[t]{2}{*}{ Alpha-I type III collagen } & COL3AI & F: AGCCAGAACGATGCCAAATATGCG & XM_003I33535.I & $654 \mathrm{bp}$ \\
\hline & & R: TGCCCTTTCATACCAGGGAATCCA & & \\
\hline \multirow[t]{2}{*}{ Alpha-I type IV collagen } & COL4AI & F: ACAGTGCCACTCTATAGCGGGTTT & XM_003131091.4 & $301 \mathrm{bp}$ \\
\hline & & R: GTTTGGCTGTGAATGGCTATGGCA & & \\
\hline \multirow[t]{2}{*}{ Tenascin } & TNC & F: TTCAGTCGGAAACAGCCCTTCTCA & NM_2I4230.I & $347 \mathrm{bp}$ \\
\hline & & R: AGAAGACTTCCAGCTTCTGGGCTT & & \\
\hline \multirow[t]{2}{*}{ Caldesmon I } & CALDI & F: AGCTTCTTCGGTGGAAAGAGGGA & XM_003I34653.I & 854 bp \\
\hline & & R: ATCAGAAGGTTXGGGAGCAGGTGA & & \\
\hline \multirow[t]{2}{*}{ Vascular endothelial growth factor $A$} & VEGFA & F: TTCTGCTCTCTTGGGTGCATTGGA & NM_2I4084.I & 296 bp \\
\hline & & R: TGATGTTGAACTCCTCAGTGGGCA & & \\
\hline Glyceraldehyde 3-phosphate & GAPDH & F: AAGGTCGGAAGTCAACGGATTTGGT & NM_00I206359.I & $450 \mathrm{bp}$ \\
\hline dehydrogenase & & R: ACAAAGTGGTGCTTGAGGGCAATG & & \\
\hline
\end{tabular}

CD44 and CD106 in engineered AVL and PVL (Figure 7A-L). Both surface markers are useful indicators of cellular in vitro senescence occurring in MSCs. As it is reported that the decreased expression of these antigens correlates with a reduced viability of their corresponding ligands (hyaluronan and TGF- $\beta$, respectively), the investigation of CD44 and CD106 could provide insights into ECM remodeling by newly synthetized proteins. As shown in Figure 7, pCMC were organized into multilayered structure, much thicker in PVL than in AVL. A comparable expression of both markers was demonstrated in constructs cultured for 7 days (D7) and 35 days (D35), indirectly suggesting the active synthesis by pCMC of structural and signaling molecules related to ECM development and turnover. In parallel, we detected also the expression of von Willebrand factor, an endothelial marker commonly correlated with in vitro re-endothelialization of decellularized heart valves (Figure 7M-R).

\section{Discussion}

Obtaining heart valve substitutes (HVs) with longer durability and functionality is still an elusive goal in clinics. Valve acellular matrices consist of nanostructured grooves, ridges, pits, pores, and fibrillary networks composed mostly of collagen and elastin fibers with diameters ranging from $100 \mathrm{~nm}$ to $300 \mathrm{~nm}$ suggesting to exert a regulatory role during tissue regeneration. Recently, new methodologies of decellularization have been experimented in tissue engineering for improving the in vivo performance of HVs. ${ }^{39}$ Mimicking the three-dimensional structure and nanotopography of native tissues, the porcine valve conduits prepared accordingly to the TriCol protocol ${ }^{16,25,26}$ demonstrated in preclinical models a great chance of success in 1) promoting a spontaneous guided tissue regeneration ${ }^{39}$ and 2) overcoming the typical drawbacks of valve graft transplantation, that is, high risk of calcification, fibrosis, and immunological reaction. ${ }^{19}$ The successful cell integration and differentiation into tissuespecific phenotypes are demonstrated to be driven by the optimized hemodynamic profile, mechanical stress, and matrikine signaling of HVs. Moreover, based on the immunophenotypic characterization of cells isolated from the explanted heart valve conduits, the complex phenomenon of valve repopulation is reported to be boosted in early phase by BM-MSCs mobilized into circulation upon surgical intervention. Our present data demonstrate that multipotent cells circulating in the peripheral blood before the implantation of TriCol valve matrices show in vitro specific responsivity to valvular structural and mechanical stimuli suggesting their potential in vivo contribution to the development of both endothelial and mesenchymal/interstitial phenotypes within valve implants.

During valve development, embryonic progenitor endothelial cells overlying the endocardial cushion undergo endothelial mesenchymal transition, giving rise to the socalled VICs, the most prevalent valve cellular phenotype of mature valves. ${ }^{40,41}$ In adult life, VICs are physiologically controlled by environmental factors, exhibit distinct cellular 


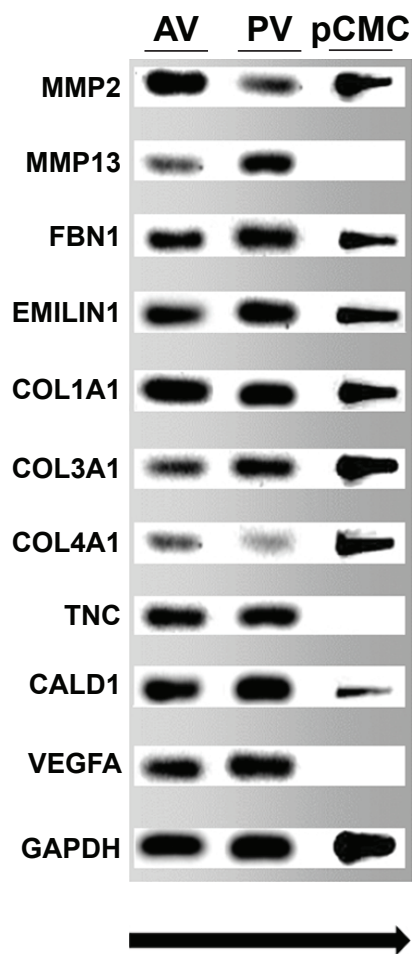

Basal expression

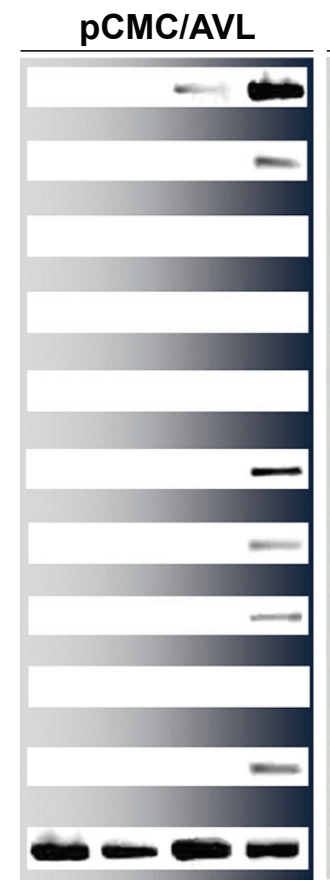

D7 D14 D28 D35

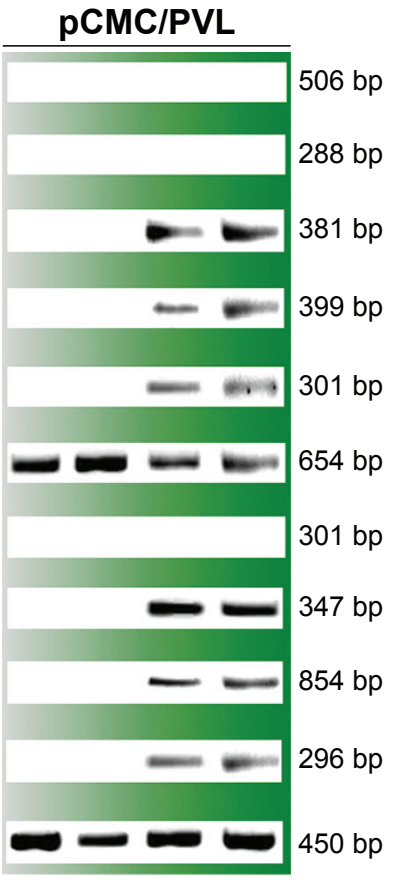

D7 D14 D28 D35

pCMC-seeded matrices

Figure 4 Gene expression study by one-step RT-PCR on RNA extracted from native heart valves (AV: aortic; PV: pulmonary), pCMC cultured on polystyrene (pCMC) or seeded on acellular aortic (AVL) and pulmonary (PVL) valve matrices (PCMC/AVL, PCMC/PVL).

Notes: Data are representative of three independent experiments performed in triplicate. The gene expression level of GAPDH housekeeping was used as reference. PCR products were electrophoresed on $2 \%$ agarose gel prestained with GelRed ${ }^{\mathrm{TM}}$ and then visualized by UV transilluminator Gel Doc 2000. Base pair: bp.

Abbreviations: RT-PCR, reverse transcription-polymerase chain reaction; PCMC, porcine circulating multipotent cells; GAPDH, glyceraldehyde 3-phosphate dehydrogenase; MMP, matrix metalloproteinase; FBNI, fibrillin; EMILINI, emilin I; COLIAI, alpha-I type I collagen; COL3AI, alpha-I type III collagen; COL4AI, alpha-I type IV collagen; TNC, tenascin C; CALDI, caldesmon I; VEGFA, vascular endothelial growth factor A.

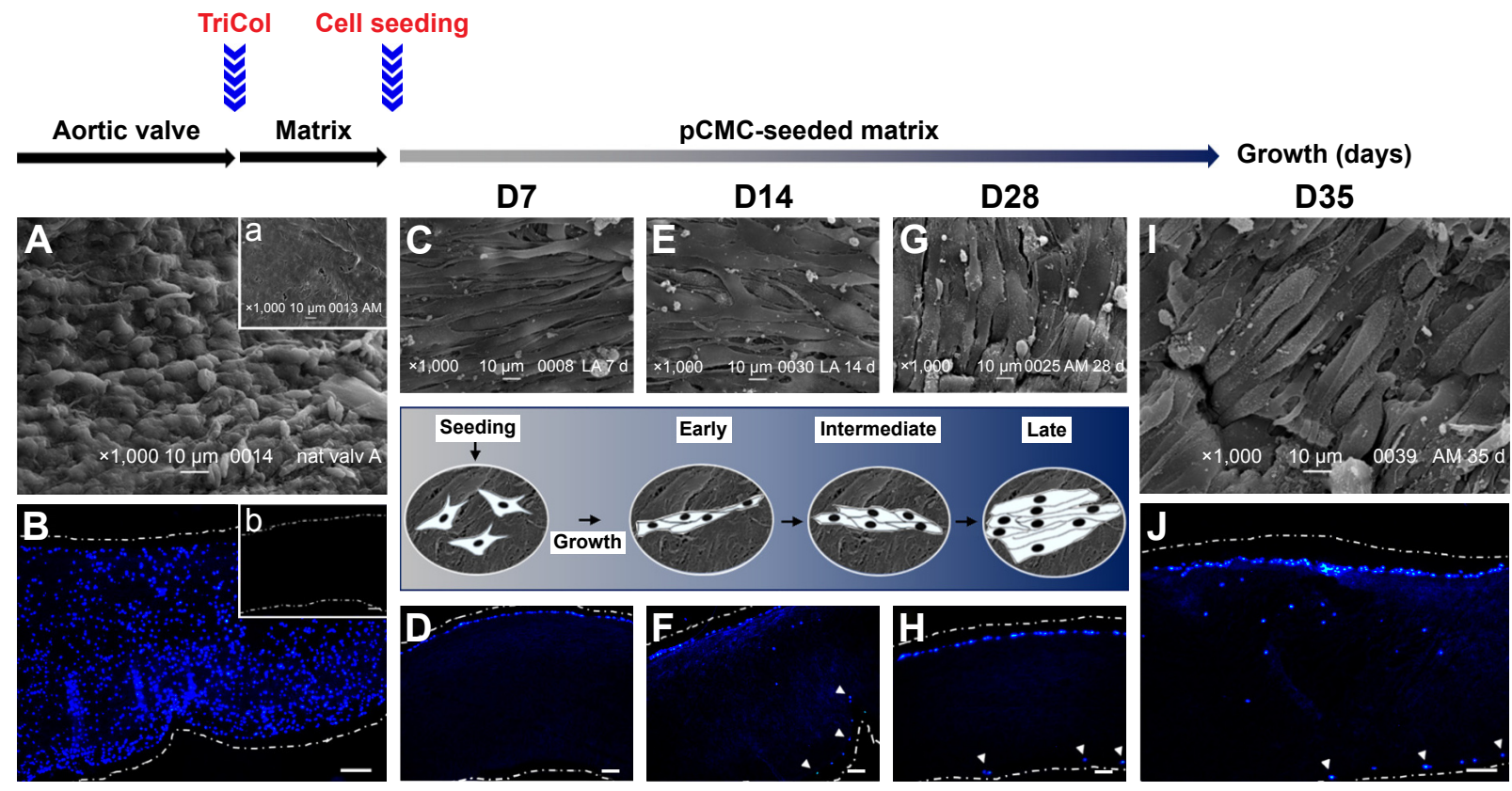

Figure 5 In vitro culture of pCMC cells on acellular aortic valve matrix.

Notes: Morphological analysis of the ventricularis layer of aortic valve before (A) and after (a) TriCol treatment. (C, E, G, I) SEM micrographs of pCMC grown on acellular aortic matrices for 7 days (D7), 14 days (DI4), 28 days (D28), and 35 days (D35). DAPI staining of $5 \mu$ m thick sections of aortic valve before (B) and after (b) decellularization to investigate the TriCol efficacy of cellular removal and $(\mathbf{D}, \mathbf{F}, \mathbf{H}, \mathbf{J})$ to track the growth of seeded pCMC during 35 days of in vitro culture. The ventricularis and fibrosa surfaces are marked by white dotted line. White arrows indicate cells grown at the fibrosa surface. In the center, the scheme illustrates the shape and alignment pattern of PCMC during in vitro culture on aortic valve leaflets. SEM magnification: I,000×; DAPI staining bar: $100 \mu \mathrm{m}$.

Abbreviations: SEM, scanning electron microscopy; PCMC, porcine circulating multipotent cells; DAPI, 4,6-diamidino-2-phenylindole. 


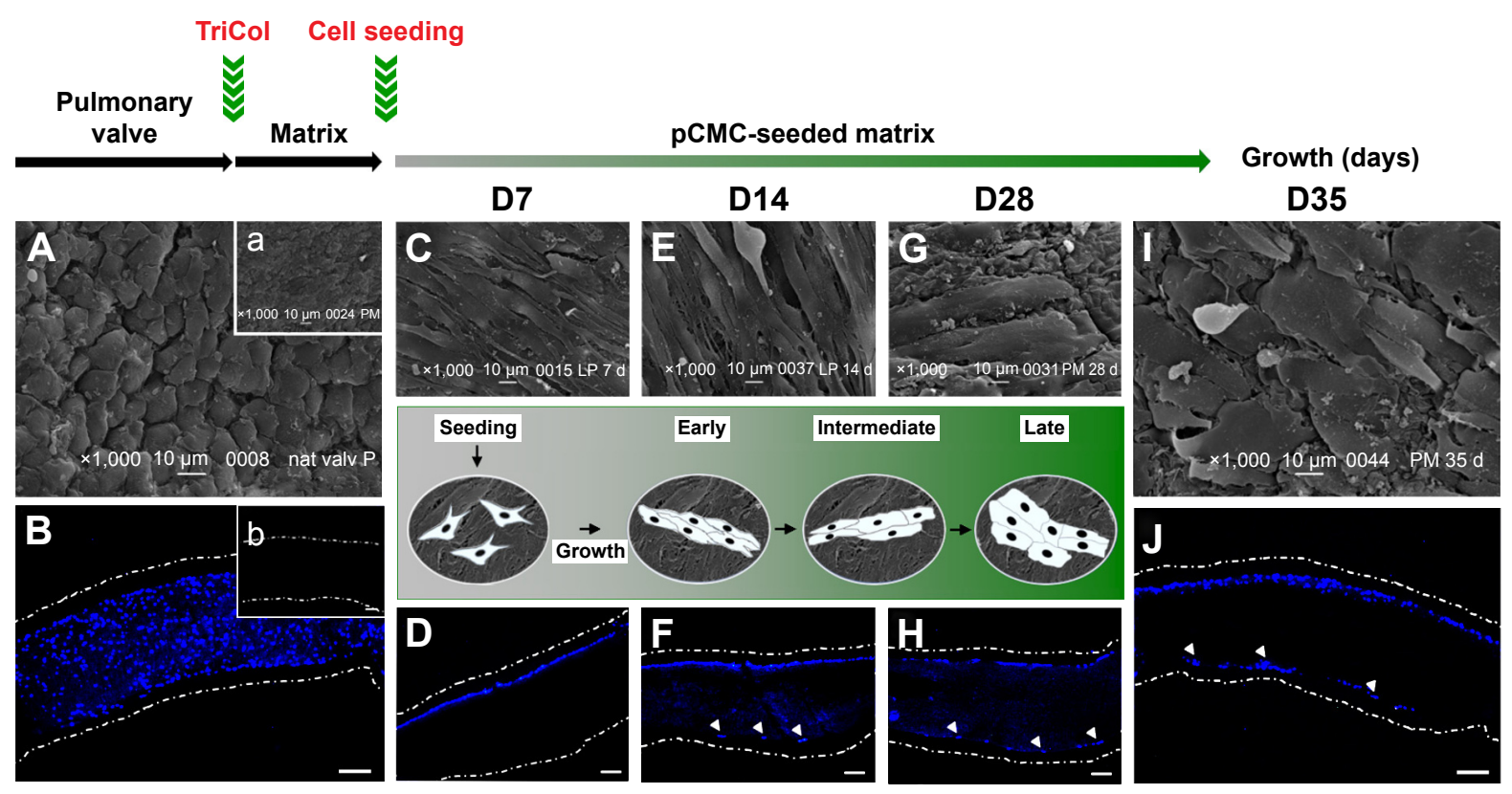

Figure 6 Morphological analysis of the ventricularis layer of pulmonary valve before (A) and after (a) TriCol treatment. (C, E, G, I) SEM micrographs of pCMC grown on acellular pulmonary matrices for 7 days (D7), I4 days (DI4), 28 days (D28), and 35 days (D35). DAPI staining of $5 \mu \mathrm{m}$ thick sections of pulmonary valve before (B) and after (b) decellularization to investigate the TriCol efficacy of cellular removal and (D, F, H, J) to track the growth and distribution of seeded pCMC during 35 days of in vitro culture.

Notes: The ventricularis and fibrosa layers are marked by white dotted line. White arrows indicate cells grown at the fibrosa surface. In the center, the scheme illustrates the shape and alignment pattern of PCMC during in vitro culture on pulmonary valve leaflets. SEM magnification: I,000x; DAPI staining bar: $100 \mu$ m.

Abbreviations: SEM, scanning electron microscopy; PCMC, porcine circulating multipotent cells; DAPI, 4,6-diamidino-2-phenylindole.

phenotypes, and are active in the control of structural integrity, remodeling, and repair of valve tissue. ${ }^{42}$ Recent findings suggest that valvular stem cells, reported as progenitor VICs (pVICs) expressing CD34 and CD133, ${ }^{43}$ should play a pivotal role in the rescue of structural and mechanical properties of valve tissue under pathological conditions or during valve regeneration. Sex-mismatched murine chimeras and multilineage hematopoietic stem cell engraftments were used to provide the evidence that hematopoietic stem cells engraft into recipient heart valves expressing mRNA for procollagen $\alpha 1$ and acquiring VICs-like phenotype. ${ }^{44}$ Although numerous attempts to identify potential pVICs have been made, at present, the evidence of circulating cells with high valvular differentiative potential is still limited. Compared to peripheral blood multipotent cells identified by other groups, such as BM-MSC, ${ }^{29,45}$ hematopoietic stem cells, ${ }^{46}$ endothelial progenitor cells, ${ }^{47,48}$ blood-derived MSCs, ${ }^{49}$ and monocyte-derived multipotential cells,$^{50} \mathrm{pCMC}$ showed similar fibroblastic morphology, ex vivo expansion potential, and multidifferentiative activities but diverged from them for immunophenotypic features. Basically consisting of endothelial/hematopoietic progenitors $\left(\mathrm{CD} 133^{+}, \mathrm{CD} 34^{+}\right)^{47}$ and MSCs $\left(\mathrm{CD}_{4} 4^{+}, \mathrm{CD}_{106}{ }^{+}, \mathrm{CD} 90^{+}, \alpha-\mathrm{SMA}^{+}\right),{ }^{51-53} \mathrm{pCMC}$ activated differential valve patterning after long-term in vitro culture on the ventricularis surface of AV and PV matrices, demonstrating to "sense" the nanopatterned surface and mechanical heterogeneity of valve scaffolds and thus to "reprogram" their functionality accordingly.

Showing hematopoietic origin $\left(\mathrm{CD} 133^{+} / \mathrm{CD} 34^{+}\right)$but not mature phenotype (CD45-), pCMC were hypothesized to derive from bone marrow. The expression of adhesion molecules such as CD44, the hyaluronan receptor, ${ }^{51}$ and $\alpha$-SMA, a contractile actin isoform, ${ }^{28,53}$ defined their ability to adhere to osteoblastic niche. In contrast, CD106 (vascular cell adhesion protein 1) and CD90 (thymus cell antigen-1) were probably indicative of their ability of extravasation and migration ${ }^{54}$ into circulation constitutively or following specific stimulation (anesthesia, trauma, surgery). The low expression of swine leukocyte antigen DR clearly confirmed the presence of a hierarchical organization in $\mathrm{pCMC}$, where multipotent stem cells could generate cells with decreased stemness grade and lineage commitment potential.

An ideal HV must serve in vivo as an initial guiding structure for cell attachment and tissue development. ECM proteins are important structural and regulatory components of tissues, and their expression and organization are critical for the correct functioning of native tissue and engineered constructs. The ECM nanostructures serve not only as a mechanical support but also as a dynamic structure providing signals and cues to adherent cells, storing and releasing growth factors, and thus controlling cellular behavior. ${ }^{13}$ Although an enormous progress has been made in understanding the 

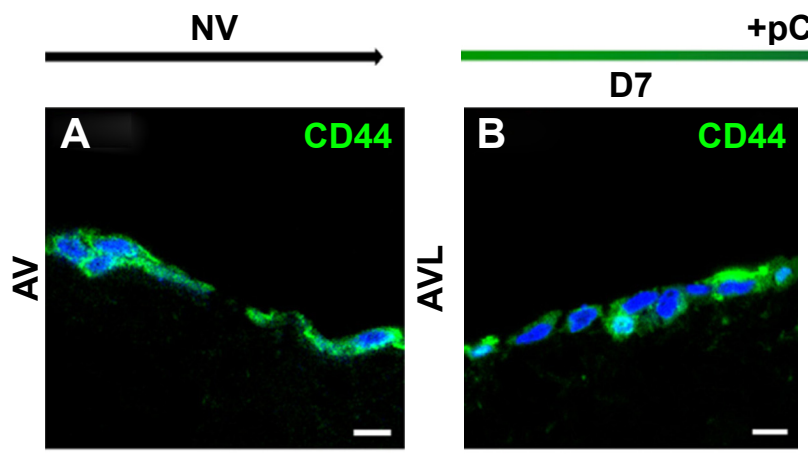

$+\mathrm{pCMC}$
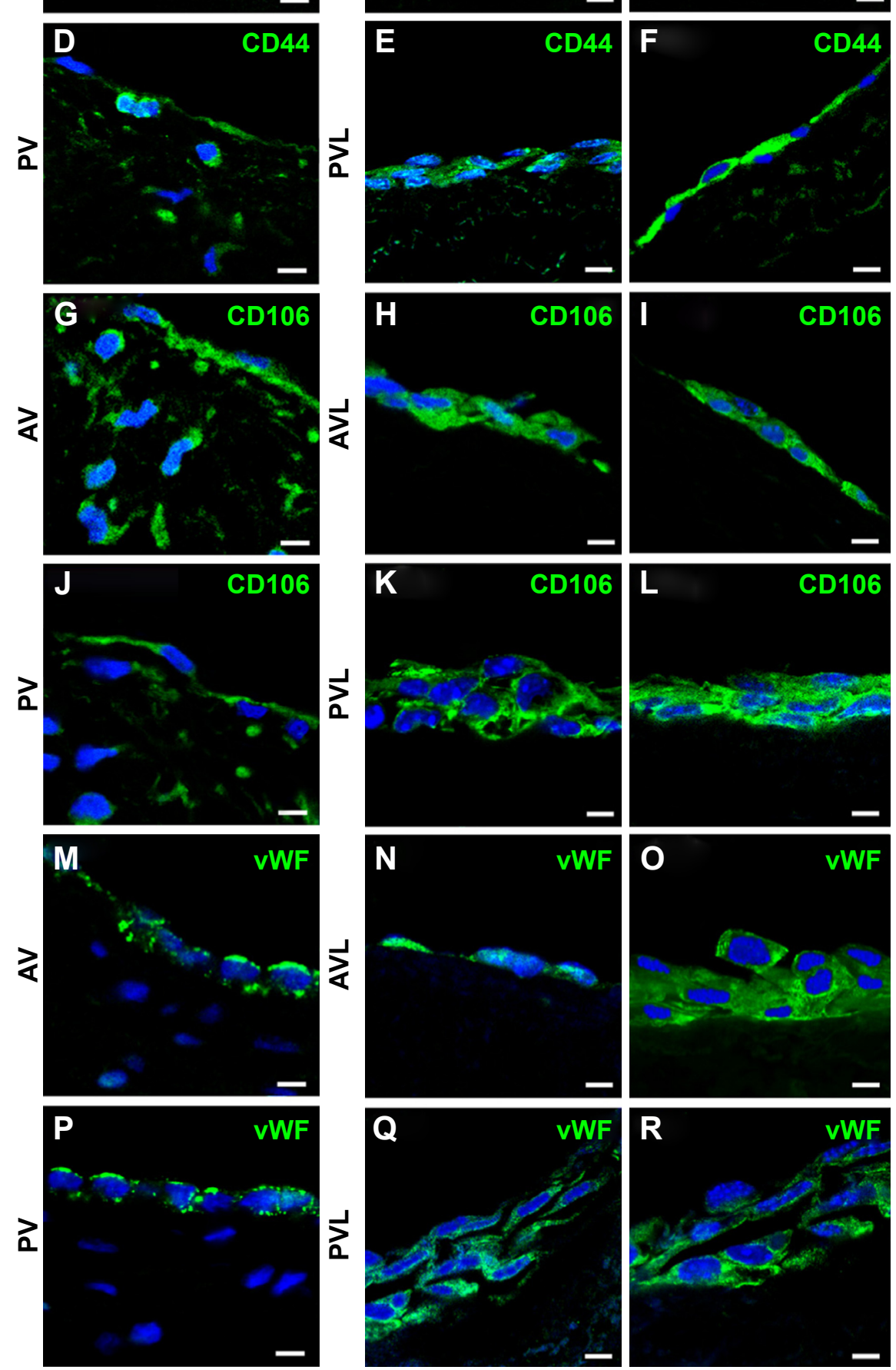

Figure 7 Immunodetection of CD44 (A-F), CDI06 (G-L), and vWF (M-R) performed on AVL and PVL seeded with PCMC and cultured in vitro for 7 days (D7) and 35 days (D35)

Notes: The expression of target markers in aortic (AV) and pulmonary (PV) native valves (NV) was also reported. Bar: $10 \mu \mathrm{m}$.

Abbreviations: PCMC, porcine circulating multipotent cells; vWF, von Willebrand factor. 
response of multipotent cells to the signaling of decellularized heart valve matrices, there are several important questions that remain unanswered concerning whether graft-colonizing stem cells could give rise to a complex three-layered network by sensing only chemical signals and nanostructures of valve ECM. In this work, TriCol matrices seeded with pCMC and cultured under no-flow condition showed to be a useful in vitro model for studying the impact of ECM hemodynamics and surface topography on the regeneration potential of valve conduits. After long-term culture, pCMC showed to be committed versus VIC- and VEC-like phenotypes on pulmonary leaflet, as suggested by the expression of structural markers typically expressed in fibrosa (collagen 1 and 3), spongiosa (TNC), ventricularis (FBN1 and emilin), and endothelium (VEGFA). Conversely, the cells responded to the different hemodynamic microenvironment and mechanical stretch of aortic heart valve conduits, ${ }^{55}$ promoting collagen remodeling through the expression of MMP2 ${ }^{56}$ and MMP13. ${ }^{57}$ Interestingly, the expression of MMP2 could suggest also an acquired migratory potentiality by $\mathrm{pCMC}$, in agreement with data reported by Shelton and Yutzey. ${ }^{58}$ As already reported in preclinical studies, ${ }^{19}$ AVs have been shown to sustain the process of endothelization by stimulating the production of VEGFA and collagen 3 and $4 .{ }^{59}$ The acquisition of VEC-like phenotype ${ }^{43}$ was further demonstrated in both leaflets by the expression of von Willebrand factor protein.

The biological response of $\mathrm{pCMC}$ could be crucial during in vivo implant regeneration as both re-endothelization and remodeling of collagenous/elastic network are essential processes to avoid thrombosis and preserve the structural/functional integrity of valve implants. Valve biology and biomechanics are strictly correlated to each other, and the nanostructural composition of the heart valve tissue determines its nonlinear stress-strain characteristics. Thus, alterations of structural components during the regeneration of valve substitutes reflect on the balance between external (blood, heart) and internal mechanical forces provoking valve dysfunction. The expression of TNC in both aortic and pulmonary conduits further suggested the great potentiality of TriCol valve matrices to sustain cellular functionality. $\mathrm{TNC}^{60}$ is a matricellular protein that is expressed in a spatiotemporal-restricted manner, during early stages of development and tissue remodeling. In our study, the expression of TNC could be indicative of an increased elasticity of matrix that is functional to preserve the implants from mechanical stretch. Taken into account that 1) elastin is essential for providing extensibility to valve tissue ${ }^{6,13}$ and 2) the explanted valve conduits from preclinical animal model evidenced no tissue disruption, the absent expression of emilin and FBN1 in aortic matrices could suggest that the decellularization method did not affect the elastic fiber. Thus, the cells could be stimulated to essentially enrich their microenvironment of collagenous matrix that is more in AV compared to pulmonary one.

In vitro studies on valves engineered with endothelial progenitor cells, smooth muscle cells, and multipotential stem cells significantly demonstrated that static and dynamic mechanical forces of decellularized matrices influence cells in viability, morphological changes, valve colonization, and biosynthetic activity. Hyaluronan is an important component of valve hydrated matrix providing physical support for mechanical function and cell migration. ${ }^{40}$ It is reported that CD106 expression downregulates in senescent $\mathrm{MSCs}^{61}$ because of the reduced synthesis of hyaluronan during in vitro culture expansion. In our work, after long-term culture, the expression of adhesion molecules CD44 and CD106 was shown to be preserved, suggesting that TriCol matrices are functional to guarantee long-term cell in vitro viability. Being expressed in undifferentiated and differentiated cells, CD44 is hypothesized to play a pivotal role in mediating the binding of pCMC to the stem cell niche and the colonization of tissues enriched of hyaluronan such as heart valves.

Finally, we also demonstrated that the morphological features of VECs could be depending not only on blood flow pressure but also on ECM/cell interactions. In agreement with data reported by Butcher and Markwald, ${ }^{41}$ SEM of pCMC showed a differential morphological pattern of response to AVL and PVL but comparable with that of VECs from native valves. In AV, VECs of both inflow and outflow layers are aligned with their long axis parallel to underlying ECM components organized circumferentially, and thus perpendicular to the direction of flow. ${ }^{62}$ In the absence of an aligned substrate, VECs align perpendicular to flow. ${ }^{63}$ Consistent with data previously reported by Butcher et al, ${ }^{64} \mathrm{pCMC}$ strongly demonstrated under static culture conditions that the adhesion of VEC cells to ECM modulates cellular shape according to internal mechanical forces. Moreover, this cellular response could involve the formation of more prominent stress fibers along the long axis of valvular cells in AV due to the robust fibrous collagenous and elastic extracellular network. Stress fibers are contractile actomyosin bundles that exert a fundamental role in various cellular processes such as morphogenesis, migration, cytokinesis, endocytosis, and phagocytosis. ${ }^{65}$ During ECM remodeling, the structure and dynamics of actin filament networks are regulated in their nucleation, elongation, and disassembly by a large array of proteins. ${ }^{66}$ In our studies, the expression of CALD ${ }^{67}$ further suggested a differential cytoskeleton reorganization driven by ECM nanopatterned structure. ${ }^{65}$ 


\section{Conclusion}

Both ECM topography and shear stresses affect cellular and tissue biological activities. Sensing the local tissue mechanical environment and ECM nanostructures, valve cells mediate specific molecular changes to maintain valve homeostasis, adapt to an altered stress state, or repair injuries through tissue remodeling. In this work, we isolated circulating multipotent cells from minipig peripheral blood and used them to explore the potential of in vitro repopulation of acellular heart valves. Based on their origin from peripheral blood, pCMC are hypothesized in vivo to exert a critical role to 1) homeostatically replenish valve cells, 2) participate in regenerative response following chemical (anesthesia) or physical (trauma) stimuli, and 3) contribute to hetero- or allograft colonization promoting the endothelialization and cell ingrowth of prosthesis. Due to their ability to sense biomechanical stress within graft and modulate transcriptional activity accordingly, pCMC could be a useful in vitro model for testing the suitability of implants for "guided tissue engineering" applications.

\section{Acknowledgments}

This study was supported by financial grants from the "Provincia di Padova", Italy, and Foundation for Biology and Regenerative Medicine, Tissue Engineering and Signaling (TES) ONLUS, Padova, Italy. The authors thank Annachiara Martinelli for technical support. Maria Teresa Conconi and Gerosa Gino are co-senior authors.

\section{Author contributions}

RDL: conception and design, data analysis and interpretation, manuscript writing, final approval of manuscript; SB, AM, AT, SS: collection and/or assembly of data; TB: collection and/or assembly of data, manuscript writing; PA, LI, AG: provision of study material or animals; PPP: financial support, administrative support, final approval of manuscript; MTC: collection and/or assembly of data, final approval of manuscript; GG: provision of study material or animals, final approval of manuscript. All authors contributed toward data analysis, drafting and critically revising the paper and agree to be accountable for all aspects of the work.

\section{Disclosure}

The authors report no conflicts of interest in this work.

\section{References}

1. Mendelson K, Schoen FJ. Heart valve tissue engineering: concepts, approaches, progress, and challenges. Ann Biomed Eng. 2006;34(12): 1799-1819.

2. von der Mark K, Park J, Bauer S, Schmuki P. Nanoscale engineering of biomimetic surfaces: cues from the extracellular matrix. Cell Tissue Res. 2010;339(1):131-153
3. Curtis ASG, Dalby M, Gadegaard N. Cell signaling arising from nanotopography: implications for nanomedical devices. Nanomedicine (Lond). 2006;1(1):67-72.

4. Gerosa G, Rizzoli G, Di Marco F, Bottio T, Thiene G, Casarotto D. The experience with porcine bioprostheses at Padua University. J Heart Valve Dis. 2004;13(suppl 1):S44-S48.

5. Yacoub MH, Takkenberg JJM. Will heart valve tissue engineering change the world? Nat Clin Pract Cardiovasc Med. 2005;2(2):60-61.

6. Schoen FJ, Levy RJ. Calcification of tissue heart valve substitutes: progress toward understanding and prevention. Ann Thorac Surg. 2005; 79(3):1072-1080.

7. Mikos AG, Herring SW, Ochareon P, et al. Engineering complex tissues. Tissue Eng. 2006;12(12):3307-3339.

8. Zilla P, Brink J, Human P, Bezuidenhout D. Prosthetic heart valves: catering for the few. Biomaterials. 2008;29(4):385-406.

9. Tillquist MN, Maddox TM. Cardiac crossroads: deciding between mechanical or bioprosthetic heart valve replacement. Patient Prefer Adherence. 2011;5:91-99.

10. Friedewald VE, Bonow RO, Borer JS, et al. The editor's roundtable: cardiac valve surgery. Am J Cardiol. 2007;99(9):1269-1278.

11. Neuenschwander S, Hoerstrup SP. Heart valve tissue engineering. Transpl Immunol. 2004;12(3-4):359-365.

12. Moroni F, Mirabella T. Decellularized matrices for cardiovascular tissue engineering. Am J Stem Cells. 2014;3(1):1-20.

13. Hasan A, Ragaert K, Swieszkowski W, et al. Biomechanical properties of native and tissue engineered heart valve constructs. J Biomech. 2014;47(9):1949-1963.

14. Sacks MS, Smith DB, Hiester ED. The aortic valve microstructure: effects of transvalvular pressure. J Biomed Mater Res. 1998;41(1): $131-141$.

15. Grauss R, Hazekamp M, van Vliet S, Gittenberger-de Groot A, DeRuiter M. Decellularization of rat aortic valve allografts reduces leaflet destruction and extracellular matrix remodeling. $J$ Thorac Cardiovasc Surg. 2003;126(6):2003-2010.

16. Iop L, Renier V, Naso F, et al. The influence of heart valve leaflet matrix characteristics on the interaction between human mesenchymal stem cells and decellularized scaffolds. Biomaterials. 2009;30(25): 4104-4116.

17. Gallo M, Bianco R, Bottio T, et al. Tissue-engineered heart valves: intraoperative protocol. J Cardiovasc Transl Res. 2013;6(4):660-661.

18. Gallo M, Naso F, Poser H, et al. Physiological performance of a detergent decellularized heart valve implanted for 15 months in Vietnamese pigs: surgical procedure, follow-up, and explant inspection. Artif Organs. 2012;36(6):E138-E150.

19. Iop L, Bonetti A, Naso F, et al. Decellularized allogeneic heart valves demonstrate self-regeneration potential after a long-term preclinical evaluation. PLoS One. 2014;9(6):e99593.

20. Elkins RC, Goldstein S, Hewitt CW, et al. Recellularization of heart valve grafts by a process of adaptive remodeling. Semin Thorac Cardiovasc Surg. 2001;13(4 suppl 1):87-92.

21. Leyh RG, Wilhelmi M, Rebe P, et al. In vivo repopulation of xenogeneic and allogeneic acellular valve matrix conduits in the pulmonary circulation. Ann Thorac Surg. 2003;75(5):1457-1463; discussion1463.

22. Kim S, Elkon KB, Ma X. Transcriptional suppression of interleukin-12 gene expression following phagocytosis of apoptotic cells. Immunity 2004;21(5):643-653.

23. Erdbrügger W, Konertz W, Dohmen PM, et al. Decellularized xenogenic heart valves reveal remodeling and growth potential in vivo. Tissue Eng. 2006;12(8):2059-2068.

24. Spina M, Ortolani F, El Messlemani A, et al. Isolation of intact aortic valve scaffolds for heart-valve bioprostheses: extracellular matrix structure, prevention from calcification, and cell repopulation features. J Biomed Mater Res A. 2003;67(4):1338-1350.

25. Naso F, Gandaglia A, Iop L, Spina M, Gerosa G. First quantitative assay of alpha-Gal in soft tissues: presence and distribution of the epitope before and after cell removal from xenogeneic heart valves. Acta Biomater. 2011;7(4):1728-1734. 
26. Bertipaglia B, Ortolani F, Petrelli L, et al. Cell characterization of porcine aortic valve and decellularized leaflets repopulated with aortic valve interstitial cells: the VESALIO project (Vitalitate Exornatum Succedaneum Aorticum Labore Ingenioso Obtenibitur). Ann Thorac Surg. 2003;75(4):1274-1282.

27. Cigliano A, Gandaglia A, Lepedda AJ, et al. Fine structure of glycosaminoglycans from fresh and decellularized porcine cardiac valves and pericardium. Biochem Res Int. 2012;2012:979351.

28. Han CI, Campbell GR, Campbell JH. Circulating bone marrow cells can contribute to neointimal formation. $J$ Vasc Res. 2001;38(2):113-119.

29. Dominici M, Le Blanc K, Mueller I, et al. Minimal criteria for defining multipotent mesenchymal stromal cells. The International Society for Cellular Therapy position statement. Cytotherapy. 2006;8(4):315-317.

30. Ferrari G, Cusella-De Angelis G, Coletta M, et al. Muscle regeneration by bone marrow-derived myogenic progenitors. Science. 1998; 279(5356):1528-1530.

31. Kucia MJ, Wysoczynski M, Wu W, Zuba-Surma EK, Ratajczak J, Ratajczak MZ. Evidence that very small embryonic-like stem cells are mobilized into peripheral blood. Stem Cells. 2008;26(8):2083-2092.

32. Kuznetsov SA, Mankani MH, Leet AI, Ziran N, Gronthos S, Robey PG. Circulating connective tissue precursors: extreme rarity in humans and chondrogenic potential in guinea pigs. Stem Cells. 2007;25(7): $1830-1839$.

33. Wan C, He Q, Li G. Allogenic peripheral blood derived mesenchymal stem cells (MSCs) enhance bone regeneration in rabbit ulna criticalsized bone defect model. J Orthop Res. 2006;24(4):610-618.

34. Huss R, Lange C, Weissinger EM, Kolb HJ, Thalmeier K. Evidence of peripheral blood-derived, plastic-adherent CD34(-/low) hematopoietic stem cell clones with mesenchymal stem cell characteristics. Stem Cells. 2000;18(4):252-260.

35. Kuznetsov SA, Mankani MH, Gronthos S, Satomura K, Bianco P, Robey PG. Circulating skeletal stem cells. J Cell Biol. 2001;153(5): $1133-1140$.

36. Wu GD, Nolta JA, Jin Y-S, et al. Migration of mesenchymal stem cells to heart allografts during chronic rejection. Transplantation. 2003; 75(5):679-685.

37. $\mathrm{He} \mathrm{Q}, \mathrm{Wan} \mathrm{C}, \mathrm{Li} \mathrm{G}$. Concise review: multipotent mesenchymal stromal cells in blood. Stem Cells. 2007;25(1):69-77.

38. Scapin G, Bertalot T, Vicentini N, et al. Neuronal commitment of human circulating multipotent cells by carbon nanotube-polymer scaffolds and biomimetic peptides. Nanomedicine (Lond). 2016;11(15):1929-1946.

39. Iop L, Gerosa G. Guided tissue regeneration in heart valve replacement: from preclinical research to first-in-human trials. Biomed Res Int. 2015;2015:432901.

40. Combs MD, Yutzey KE. Heart valve development: regulatory networks in development and disease. Circ Res. 2009;105(5):408-421.

41. Butcher JT, Markwald RR. Valvulogenesis: the moving target. Philos Trans R Soc Lond B Biol Sci. 2007;362(1484):1489-1503.

42. Schoen FJ. Evolving concepts of cardiac valve dynamics: the continuum of development, functional structure, pathobiology, and tissue engineering. Circulation. 2008;118(18):1864-1880.

43. Liu AC, Joag VR, Gotlieb AI. The emerging role of valve interstitial cell phenotypes in regulating heart valve pathobiology. Am J Pathol. 2007; 171(5):1407-1418.

44. Visconti RP, Ebihara Y, LaRue AC, et al. An in vivo analysis of hematopoietic stem cell potential: hematopoietic origin of cardiac valve interstitial cells. Circ Res. 2006;98(5):690-696.

45. Boxall SA, Jones E. Markers for characterization of bone marrow multipotential stromal cells. Stem Cells Int. 2012;2012:975871.

46. Pouzolles M, Oburoglu L, Taylor N, Zimmermann VS. Hematopoietic stem cell lineage specification. Curr Opin Hematol. 2016;23(4):311-317.

47. Yoder MC, Mead LE, Prater D, et al. Redefining endothelial progenitor cells via clonal analysis and hematopoietic stem/progenitor cell principals. Blood. 2007;109(5):1801-1809.
48. Yoder MC. Human endothelial progenitor cells. Cold Spring Harb Perspect Med. 2012;2(7):a006692.

49. Li S, Huang K-J, Wu J-C, et al. Peripheral blood-derived mesenchymal stem cells: candidate cells responsible for healing critical-sized calvarial bone defects. Stem Cells Transl Med. 2015;4(4):359-368.

50. Kuwana M, Okazaki Y, Kodama H, Satoh T, Kawakami Y, Ikeda Y. Endothelial differentiation potential of human monocyte-derived multipotential cells. Stem Cells. 2006;24(12):2733-2743.

51. Noort WA, Oerlemans MIFJ, Rozemuller H, et al. Human versus porcine mesenchymal stromal cells: phenotype, differentiation potential, immunomodulation and cardiac improvement after transplantation. J Cell Mol Med. 2012;16(8):1827-1839.

52. Fukiage K, Aoyama T, Shibata KR, et al. Expression of vascular cell adhesion molecule-1 indicates the differentiation potential of human bone marrow stromal cells. Biochem Biophys Res Commun. 2008; 365(3):406-412.

53. Kinner B, Zaleskas JM, Spector M. Regulation of smooth muscle actin expression and contraction in adult human mesenchymal stem cells. Exp Cell Res. 2002;278(1):72-83.

54. Gonda A, Gál I, Szántó S, et al. CD44, but not 1-selectin, is critically involved in leucocyte migration into the skin in a murine model of allergic dermatitis. Exp Dermatol. 2005;14(9):700-708.

55. Naso F, Gandaglia A, Formato M, et al. Differential distribution of structural components and hydration in aortic and pulmonary heart valve conduits: impact of detergent-based cell removal. Acta Biomater. 2010;6(12):4675-4688.

56. Soini Y, Satta J, Määttä M, Autio-Harmainen H. Expression of MMP2, MMP9, MT1-MMP, TIMP1, and TIMP2 mRNA in valvular lesions of the heart. J Pathol. 2001;194(2):225-231.

57. Rabkin-Aikawa E, Farber M, Aikawa M, Schoen FJ. Dynamic and reversible changes of interstitial cell phenotype during remodeling of cardiac valves. $J$ Heart Valve Dis. 2004;13(5):841-847.

58. Shelton EL, Yutzey KE. Twist1 function in endocardial cushion cell proliferation, migration, and differentiation during heart valve development. Dev Biol. 2008;317(1):282-295.

59. Lichtenberg A, Tudorache I, Cebotari S, et al. In vitro re-endothelialization of detergent decellularized heart valves under simulated physiological dynamic conditions. Biomaterials. 2006;27(23):4221-4229.

60. Imanaka-Yoshida $\mathrm{K}$, Aoki $\mathrm{H}$. Tenascin-C and mechanotransduction in the development and diseases of cardiovascular system. Front Physiol. 2014;5:283.

61. Jung EM, Kwon O, Kwon K-S, et al. Evidences for correlation between the reduced VCAM-1 expression and hyaluronan synthesis during cellular senescence of human mesenchymal stem cells. Biochem Biophys Res Commun. 2011;404(1):463-469.

62. Deck JD. Endothelial cell orientation on aortic valve leaflets. Cardiovasc Res. 1986;20(10):760-767.

63. Butcher JT, Nerem RM. Valvular endothelial cells regulate the phenotype of interstitial cells in co-culture: effects of steady shear stress. Tissue Eng. 2006;12(4):905-915.

64. Butcher JT, Penrod AM, García AJ, Nerem RM. Unique morphology and focal adhesion development of valvular endothelial cells in static and fluid flow environments. Arterioscler Thromb Vasc Biol. 2004; 24(8):1429-1434.

65. Pollard TD, Cooper JA. Actin, a central player in cell shape and movement. Science. 2009;326(5957):1208-1212

66. Tojkander S, Gateva G, Lappalainen P. Actin stress fibers - assembly, dynamics and biological roles. J Cell Sci. 2012;125(pt 8):1855-1864.

67. O'Connor JW, Gomez EW. Cell adhesion and shape regulate TGF-beta1-induced epithelial-myofibroblast transition via MRTF-A signaling. PLoS One. 2013;8(12):e83188. 


\section{Supplementary material}

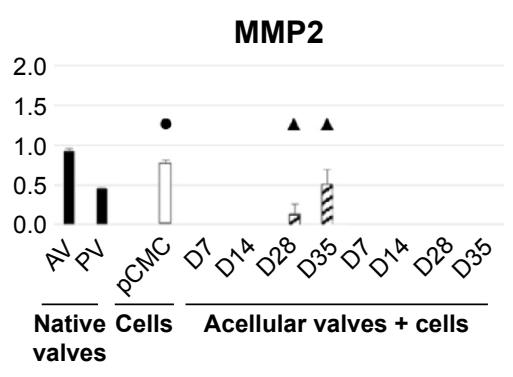

EMILIN1

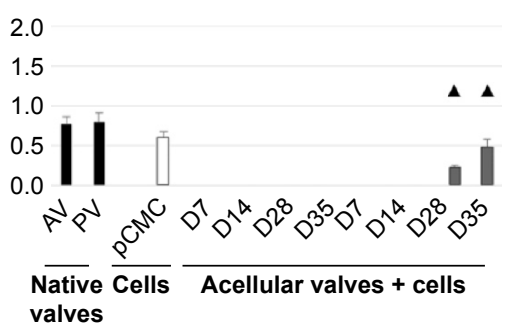

COL4A1

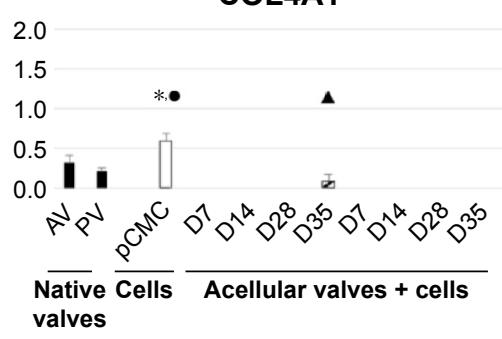

MMP13

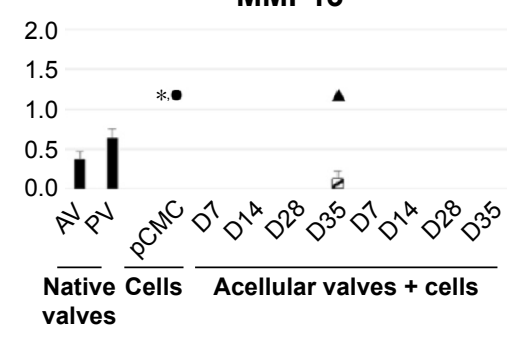

COL1A1

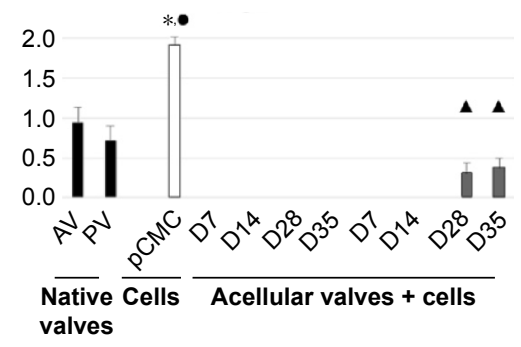

TNC

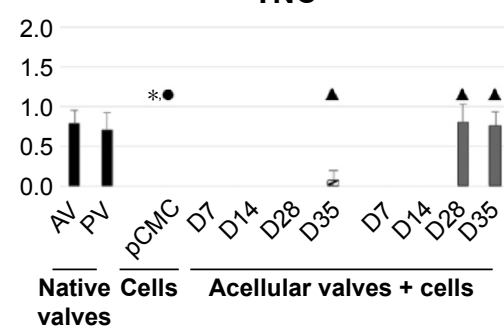

FBN1

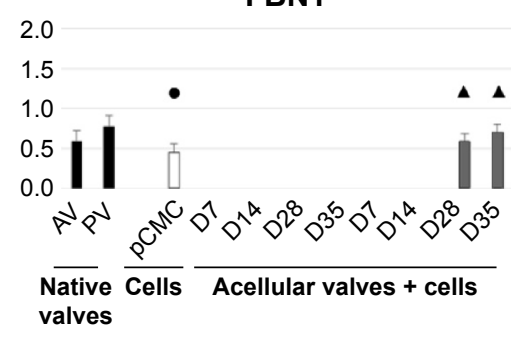

COL3A1

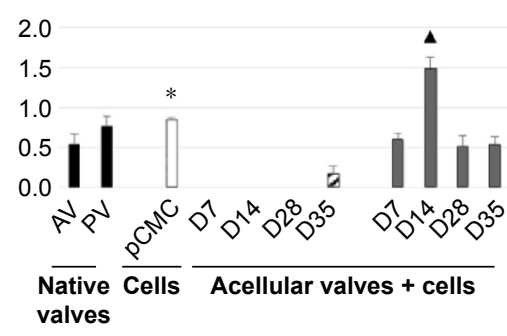

CALD1

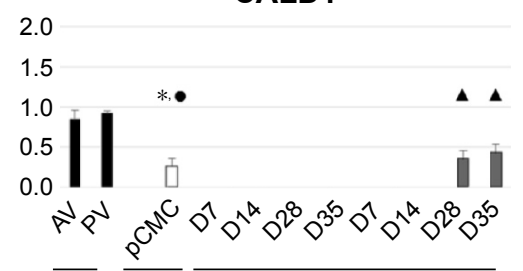

Native $\overline{\text { Cells }} \overline{\text { Acellular valves + cells }}$ valves
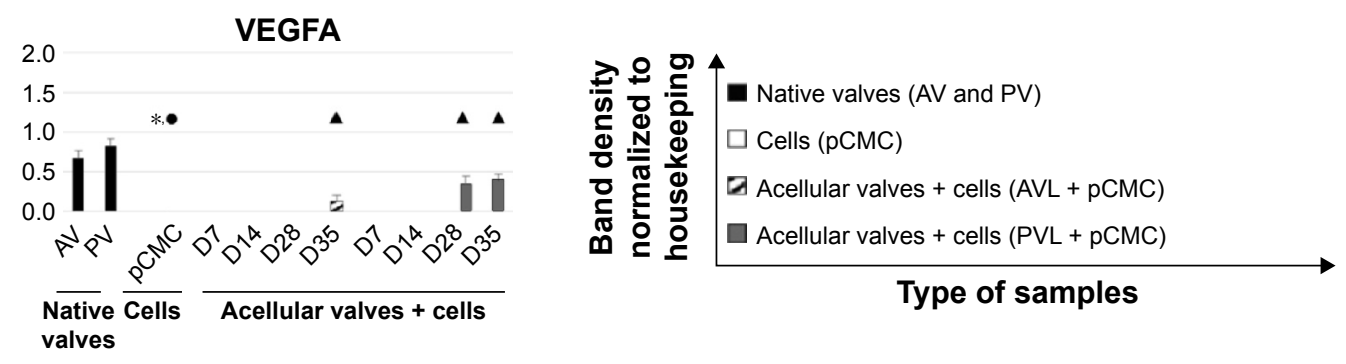

Type of samples

Figure SI Data from one-step RT-PCR analysis were analyzed using ImageLab software.

Notes: The quantification of amplicon density band was measured for each target gene considering three independent experiments performed in triplicate. Expression levels were reported as ratio within target and housekeeping (GAPDH) gene expression level. Statistical significance was calculated by the Wilcoxon test comparing the expression profile of I) PCMC grown on polystyrene dishes and control native valves ( $\mathrm{AV}, * \mathrm{P} \leq 0.05)$ and (PV, $\bullet P \leq 0.05)$, or 2) $\mathrm{PCMC}$ cultured on valve leaflets against samples cultured for 7 days $(D 7)(\triangle P \leq 0.05)$.

Abbreviations: RT-PCR, reverse transcription-polymerase chain reaction; GAPDH, glyceraldehyde 3-phosphate dehydrogenase; pCMC, porcine circulating multipotent cells; MMP, matrix metalloproteinase; FBNI, fibrillin; EMILINI, emilin I; COLIAI, alpha-I type I collagen; COL3AI, alpha-I type III collagen; COL4AI, alpha-I type IV collagen; TNC, tenascin C; CALDI, caldesmon I; VEGFA, vascular endothelial growth factor A.

International Journal of Nanomedicine

\section{Publish your work in this journal}

The International Journal of Nanomedicine is an international, peerreviewed journal focusing on the application of nanotechnology in diagnostics, therapeutics, and drug delivery systems throughout the biomedical field. This journal is indexed on PubMed Central,

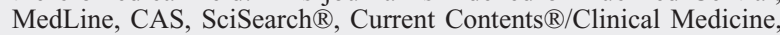

\section{Dovepress}

\footnotetext{
Submit your manuscript here: http://www.dovepress.com/international-journal-of-nanomedicine-journal
}

Journal Citation Reports/Science Edition, EMBase, Scopus and the Elsevier Bibliographic databases. The manuscript management system is completely online and includes a very quick and fair peer-review system, which is all easy to use. Visit http://www.dovepress.com/ testimonials.php to read real quotes from published authors. 